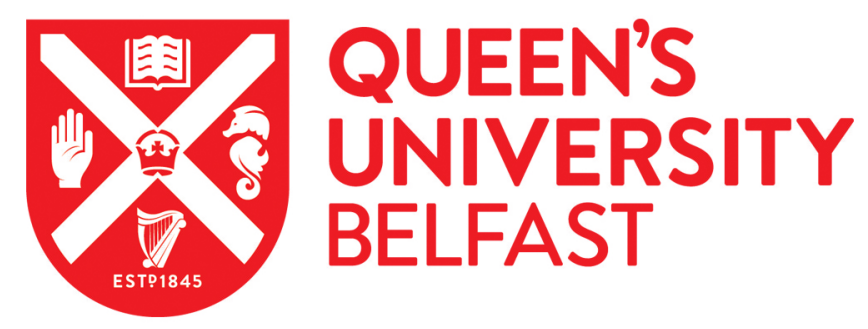

\title{
Electron transfer kinetics on mono- and multilayer graphene
}

Velický, M., Bradley, D. F., Cooper, A. J., Hill, E. W., Kinloch, I. A., Mishchenko, A., Novoselov, K. S., Patten, H. V., Toth, P. S., Valota, A. T., Worrall, S. D., \& Dryfe, R. A. W. (2014). Electron transfer kinetics on mono- and multilayer graphene. ACS Nano, 8(10), 10089-10100. https://doi.org/10.1021/nn504298r

\section{Published in:}

ACS Nano

\section{Document Version:}

Publisher's PDF, also known as Version of record

\section{Queen's University Belfast - Research Portal:}

Link to publication record in Queen's University Belfast Research Portal

\section{Publisher rights}

Copyright 2014 the authors.

This is an open access article published under a Creative Commons Attribution License (https://creativecommons.org/licenses/by/3.0/), which permits unrestricted use, distribution and reproduction in any medium, provided the author and source are cited.

\section{General rights}

Copyright for the publications made accessible via the Queen's University Belfast Research Portal is retained by the author(s) and / or other copyright owners and it is a condition of accessing these publications that users recognise and abide by the legal requirements associated with these rights.

\section{Take down policy}

The Research Portal is Queen's institutional repository that provides access to Queen's research output. Every effort has been made to ensure that content in the Research Portal does not infringe any person's rights, or applicable UK laws. If you discover content in the Research Portal that you believe breaches copyright or violates any law, please contact openaccess@qub.ac.uk. 


\title{
Electron Transfer Kinetics on Mono- and Multilayer Graphene
}

\author{
Matěj Velický, ${ }^{\dagger}$ Dan F. Bradley, ${ }^{\ddagger}$ Adam J. Cooper, ${ }^{\dagger}$ Ernie W. Hill, ${ }^{\S}$ lan A. Kinloch," Artem Mishchenko, ${ }^{\perp}$ \\ Konstantin S. Novoselov, ${ }^{\perp}$ Hollie V. Patten, ${ }^{\dagger}$ Peter S. Toth, ${ }^{\dagger}$ Anna T. Valota, ${ }^{\dagger}$ Stephen D. Worrall, ${ }^{\dagger}$ and \\ Robert A. W. Dryfe ${ }^{*, t}$
}

${ }^{\dagger}$ School of Chemistry, ${ }^{\S}$ School of Computer Science, "School of Materials, ${ }^{\perp}$ School of Physics and Astronomy, University of Manchester, Oxford Road, Manchester M13 9PL, United Kingdom and ${ }^{\ddagger}$ Department of Chemistry, University of Liverpool, Crown Street, Liverpool L69 7ZD, United Kingdom

\begin{abstract}
Understanding of the electrochemical properties of graphene, especially the electron transfer kinetics of a redox reaction between the graphene surface and a molecule, in comparison to graphite or other carbon-based materials, is essential for its potential in energy conversion and storage to be realized. Here we use voltammetric determination of the electron transfer rate for three redox mediators, ferricyanide, hexaammineruthenium, and hexachloroiridate
\end{abstract}
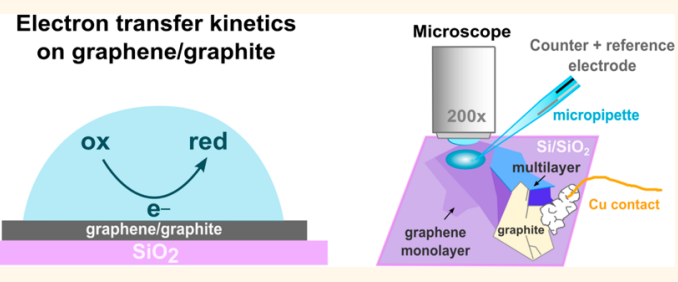
$\left(\mathrm{Fe}(\mathrm{CN})_{6}{ }^{3-}, \mathrm{Ru}\left(\mathrm{NH}_{3}\right)_{6}{ }^{3+}\right.$, and $\mathrm{IrCl}_{6}{ }^{2-}$, respectively), to measure the reactivity of graphene samples prepared by mechanical exfoliation of natural graphite. Electron transfer rates are measured for varied number of graphene layers (1 to ca. 1000 layers) using microscopic droplets. The basal planes of mono- and multilayer graphene, supported on an insulating $\mathrm{Si}_{/} \mathrm{SiO}_{2}$ substrate, exhibit significant electron transfer activity and changes in kinetics are observed for all three mediators. No significant trend in kinetics with flake thickness is discernible for each mediator; however, a large variation in kinetics is observed across the basal plane of the same flakes, indicating that local surface conditions affect the electrochemical performance. This is confirmed by

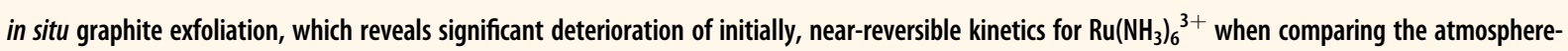
aged and freshly exfoliated graphite surfaces.

KEYWORDS: graphene $\cdot$ graphite $\cdot$ basal plane $\cdot$ electron transfer $\cdot$ kinetics $\cdot$ electrochemistry $\cdot$ voltammetry

$\longrightarrow{ }^{i n t}$ raphene has attracted significant interest due to its unique properties, namely, record charge carrier mobility, ${ }^{1}$ high thermal conductivity, ${ }^{2}$ and mechanical strength, ${ }^{3}$ discovered following its isolation in 2004. ${ }^{4}$ While applications of graphene in high-frequency transistors, flexible touch screens or photodetectors ${ }^{5,6}$ will require high-quality material, other properties of this two-dimensional (2D) nanomaterial, such as high specific surface area, optical transparency, ${ }^{7}$ and the ability to sustain large current densities, ${ }^{8}$ can be exploited using medium-quality material. Proposed applications include corrosion protection, ${ }^{9}$ sensing and biotechnology, ${ }^{10}$ and energy conversion/storage, i.e. Li-ion batteries, ${ }^{11}$ solar cells, ${ }^{12}$ and supercapacitors. ${ }^{13}$ To evaluate graphene's performance as an electrode material, the heterogeneous electron transfer (ET) rate between graphene surfaces and a redox mediator, $k^{0}$, has to be determined and compared with its three-dimensional (3D) relative-graphite. Furthermore, the difference in ET kinetics at the basal planes, edges and defects of graphitic materials has been a topic of considerable scientific interest even before the discovery of graphene. ${ }^{14,15}$ The literature, however, offers some contrasting views on the reactivity of mono- and multilayer graphene. Early ET measurements on individual graphene sheets were first reported by Li et al., ${ }^{16}$ using both mechanically exfoliated (ME) and chemical vapor deposition (CVD) grown flakes with ferrocenemethanol (FcMeOH) redox mediator, and Valota et al., ${ }^{17}$ using $\mathrm{ME}$ flakes and $\mathrm{Fe}(\mathrm{CN})_{6}{ }^{3-}$ : both reported accelerated kinetics on monolayer compared to bilayer samples $(\sim 2 \text {-fold })^{17}$ and graphite $(\sim 10$-fold $){ }^{16}$ respectively. Reactivity toward ET has been probed with Raman spectroscopy to measure the extent of diazonium functionalization of ME graphene: the reactivity of the monolayer was again found to be higher than bi- and multilayers; similarly the diazonium reduction kinetics on the edge were faster than those on the basal plane. ${ }^{18}$

ME yields high-quality flakes of pristine surface with limited contamination, allowing
* Address correspondence to robert.dryfe@manchester.ac.uk.

Received for review May 23, 2014 and accepted October 7, 2014.

Published online October 07, 2014 10.1021/nn504298r

() 2014 American Chemical Society 
the fundamental electrochemical properties of graphene to be explored. Nevertheless, ME preparation is laborious, requires "hunting" for flakes, reliable contacting/masking of the electrode, and is further complicated by fracture of monolayer graphene upon exposure to many aqueous and organic solutions. ${ }^{19}$ Most reports of graphene electrochemistry use a mixture of graphene platelets of various thicknesses and lateral dimensions, usually prepared via liquid-phase exfoliation or reduction of graphene oxide, immobilized on a conducting substrate. ${ }^{20-22}$ While this method is convenient for characterization of graphene composites, sensing layers or paints, it does not provide insight into electrochemical activity of individual graphene flakes and the roles of the basal/edge plane and defects, due to the sample's polycrystalline nature and the presence of the underlying conductor. Also, the discontinuous nature of the platelet mixture results in poor conductivity in thin samples. ${ }^{23}$ Brownson et al. reported slow ET kinetics for samples with a high basalto-edge plane ratio (for $\mathrm{Fe}(\mathrm{CN})_{6}{ }^{3-}{ }^{3}, \mathrm{Ru}\left(\mathrm{NH}_{3}\right)_{6}{ }^{3+}$, and two other mediators). ${ }^{20}$ Similarly, Zhang et al. reported extremely high $k^{0}$ for $\mathrm{Fe}(\mathrm{CN})_{6}{ }^{3-}$ and $\mathrm{Ru}\left(\mathrm{NH}_{3}\right)_{6}{ }^{3+}$ on reduced graphene oxide $\left(\sim 1\right.$ and $10 \mathrm{~cm} \mathrm{~s}^{-1}$, respectively) attributed to edges and defects. ${ }^{24}$ Ambrosi et al. found that open graphene edges exhibit faster kinetics than folded edges $\left(\mathrm{Fe}(\mathrm{CN})_{6}{ }^{3-}\right)_{1}{ }^{25}$ while Goh and Pumera concluded that the ET rate is independent of the number of graphene layers (dopamine and ascorbic acid mediators). ${ }^{21}$

CVD grown graphene has also been a popular choice for ET studies, either using the original growth substrate (typically $\mathrm{Cu}$ or $\mathrm{Ni})^{26}$ or following transfer onto an insulating substrate as shown for $\mathrm{Fe}(\mathrm{CN})_{6}{ }^{3-}$ and $\mathrm{IrCl}_{6}{ }^{2-}$ mediators. ${ }^{27}$ The underlying conductive substrate or chemicals used during the flake transfer, however, can interfere with the electrochemical response. Considerable advances have been made with the employment of scanning electrochemical microscopy (SECM), which can be efficiently used to monitor the electrochemical response of a surface with submicrometer scale spatial resolution. Tan et al. reported increased ET rates on mechanically and chemically induced defects, in comparison to the pristine graphene surface, using $\mathrm{FcMeOH}$ and $\mathrm{Fe}(\mathrm{CN})_{6}{ }^{3-} \cdot{ }^{28}$ The same group followed with an extensive study in both aqueous and organic solutions, demonstrating finite to near-reversible kinetics ( $k^{0}$ between $\sim 10^{-4}$ to $10^{-2} \mathrm{~cm} \mathrm{~s}^{-1}$ ) of 10 different redox mediators including $\mathrm{FcMeOH}, \mathrm{Fe}(\mathrm{CN})_{6}{ }^{3-}$ and $\mathrm{Ru}\left(\mathrm{NH}_{3}\right)_{6}{ }^{3+}$, with the limits in kinetics being inherent both to graphene and the nature of the mediator. ${ }^{29}$ A variant of SECM, scanning electrochemical cell microscopy (SECCM), was used successfully by Güell et al., who reported increasing ET kinetics with increasing number of CVD stacked graphene layers (from 1 to 7) using a ferrocene derivative as a mediator. Furthermore, no increase of the ET rate was observed by these authors at the edges or steps in comparison to the basal planes. $^{30}$

From the above summary, it is clear that despite the significant body of literature on graphene and graphite electrochemistry, the fundamental ET behavior on these surfaces is not fully understood. Even previously unquestionable views, such as accelerated electrode kinetics on the edges/steps relative to basal planes, are not now unanimously accepted. Here, we present electrochemically determined heterogeneous ET rates from a large number of high-quality ME flakes, deposited on insulating oxide-covered silicon wafers. The experiments were carried out in a microdroplet thinlayer cell configuration, reported earlier for CVD grown graphene on $\mathrm{Si} / \mathrm{SiO}_{2}{ }^{27}$ and mechanically exfoliated graphene on polymer substrate, ${ }^{19}$ which allows for the accurate and controlled deposition of a liquid containing redox mediator on a specific surface site. A photograph and a schematic of the experimental setup are shown in Figure 1. The work was driven by the need for a systematic study of high-quality flakes of varied thicknesses between monolayer graphene and bulk graphite, in this case about 1000 graphene layers thick. Using this method, we found that the ET activity of the pristine basal plane of graphene/graphite flakes, free from microscopic defects, varies significantly across the surface of the same crystal. This variation is attributed to airborne or solution-based contamination which affects the electrochemical performance and masks any underlying trend in ET dependence on graphene thickness. Significantly, the ET kinetics measured on in situ cleaved graphite is almost 2 orders of magnitude faster than average kinetics on atmosphere-aged samples. These insights could explain the striking number of contradictory results on both graphene and graphite surface in recent literature.

\section{RESULTS AND DISCUSSION}

Cyclic Voltammetry on Basal Plane Graphene/Graphite. The droplets containing a redox mediator (either Fe$(\mathrm{CN})_{6}{ }^{3-}$, $\mathrm{Ru}\left(\mathrm{NH}_{3}\right)_{6}{ }^{3+}$, or $\mathrm{IrCl}_{6}{ }^{2-}$, each at a concentration of $3 \mathrm{mM}$ ) dissolved in $6 \mathrm{M} \mathrm{LiCl}$ aqueous solution, were deposited on the basal plane of the graphene flake and a series of cyclic voltammograms (CV) were recorded as shown in Figure 2. CVs of electron transfer between a bilayer graphene electrode and ferri/ferrocyanide $\left(\mathrm{Fe}(\mathrm{CN})_{6}{ }^{3-/ 4-}\right)$ with the corresponding reduction and oxidation of the mediator species, are shown in Figure 2 a. The quasi-reversible nature of a reaction, where ET rate is comparable with diffusion rate, results in a peak-to-peak separation $\left(\Delta E_{\mathrm{p}}\right)$ increase with scan rate $(v)$ and allows the heterogeneous ET rate $\left(k^{0}\right)$ to be determined, using the analysis developed by Nicholson. ${ }^{31}$

$$
\psi=k^{0}\left(\frac{D_{\mathrm{O}}}{D_{\mathrm{R}}}\right)^{\alpha / 2} \sqrt{\frac{R T}{\pi n F D_{\mathrm{O}} v}}
$$



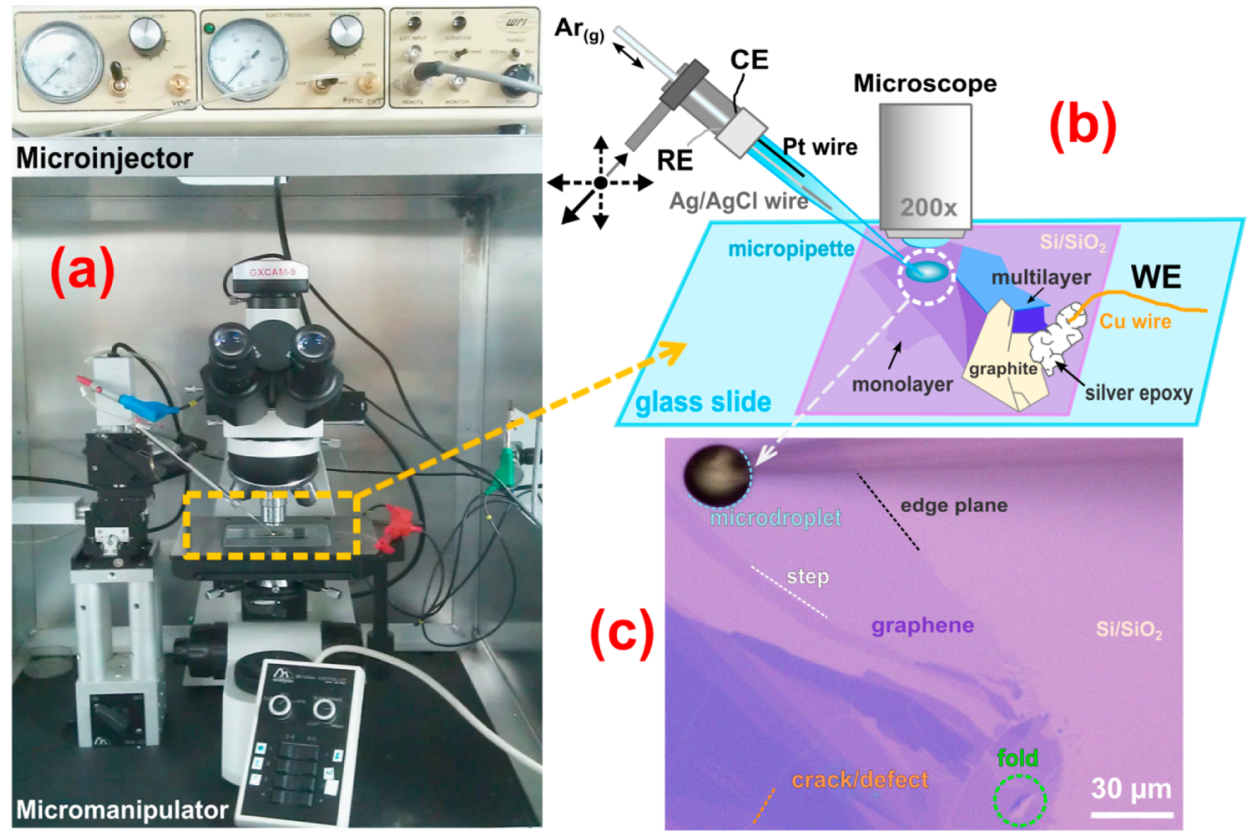

Figure 1. Experimental setup. (a) Photograph of the experimental setup. (b) Schematic depicting the $\mathrm{Si} / \mathrm{SiO}_{2}$ wafer with mechanically exfoliated flakes (working electrode, WE) contacted via silver epoxy and copper wire, microscope objective and a micropipette, which contains reference (RE) and counter electrodes (CE) and is connected to a micromanipulator and microinjector. (c) An optical micrograph of a droplet deposited on the surface of a monolayer graphene flake. The dashed lines and curves indicate edge planes (black), steps (white), cracks/defects (orange), folds (green), and microdroplet/flake interface (blue).

where $\psi$ is the dimensionless kinetic parameter determined from $\Delta E_{\mathrm{p}}, \alpha$ is the transfer coefficient, $n$ is the number of electrons transferred, $F$ is the Faraday constant, and $R$ and $T$ have their usual meanings. In most cases, it can be assumed that the diffusion coefficients of the oxidized and reduced form $\left(D_{\mathrm{O}}\right.$ and $D_{R}$, respectively) of the mediator are approximately equal and the reduction/oxidation kinetics are fairly symmetrical ( $\alpha \sim 0.5$ ). In that case, $\Delta E_{\mathrm{p}}$ depends solely on $\psi$ (one-electron processes), ${ }^{31}$ the latter is determined from $\Delta E_{\mathrm{p}}$, and eq 1 can be simplified to

$$
\psi=k^{0} \sqrt{\frac{R T}{\pi F D}} v^{-0.5}
$$

In practice, $\psi$ is calculated from $\Delta E_{\mathrm{p}}$ using an appropriate working function and $k^{0}$ determined from the slope of the $\psi-v^{-0.5}$ dependence corresponding to eq 2 as shown in Figure 2e.

Full details of the Nicholson method can be found in the Supporting Information. While the working curve defined using this approach is limited to $\Delta E_{\mathrm{p}}$ below ca. $220 \mathrm{mV}$, a method developed by Klingler and Kochi allows much larger $\Delta E_{\mathrm{p}}$ to be used for $k^{0}$ evaluation. The following expression, which is derived under assumptions of electrode reaction irreversibility, can be used to directly calculate $k^{0}$ from the scan rate and $\Delta E_{\mathrm{p}}$, and is reliable for $\Delta E_{\mathrm{p}} \sim 150 \mathrm{mV}$ and beyond: ${ }^{32}$

$$
k^{0}=2.18\left(\frac{\alpha n F D v}{R T}\right)^{1 / 2} \mathrm{e}^{-\left[\left(\alpha^{2} F / R T\right) n \Delta E_{\mathrm{p}}\right]}
$$

As in the case of Nicholson analysis, it was assumed that the reduction and oxidation are symmetrical, i.e., $\alpha \approx 0.5$. The method was also validated by finiteelement simulation of the voltammograms (Figure S4, Supporting Information).

The diffusion coefficient, required for the above analyses can be determined from the Randles-Ševčík equation, which relates the peak current, $I_{p}$, to the scan rate for the case of planar diffusion: ${ }^{33}$

$$
I_{\mathrm{p}}=0.4463\left(\frac{n^{3} F^{3}}{R T}\right)^{1 / 2} A D^{1 / 2} c v^{1 / 2}
$$

where $A$ is the area of the flake surface in contact with the liquid and $c$ is the bulk concentration of the mediator. Although eq 4 has been widely used by researchers to determine diffusion coefficients during ET rate measurements, it is only strictly valid for reversible electrochemical reactions, i.e., where ET kinetics are significantly faster than mass-transport. The peak current in quasi-reversible reactions, as is the case here, is no longer proportional to $v^{1 / 2}$ and instead more complex analysis is required to describe the peak current, with the quasi-reversible reaction zone corresponding to $\Delta E_{\mathrm{p}}$ of $\sim 62 / n$ to $1000 / \mathrm{n} \mathrm{mV}^{34}$ We also found that the linear $\psi-v^{-0.5}$ dependence breaks down when the droplet is significantly smaller than $20 \mu \mathrm{m}$ in diameter and/or the scan rate is decreased below $100 \mathrm{mV} \mathrm{s}{ }^{-1}$, most likely due to a deviation from the ideal semi-infinite linear diffusion 

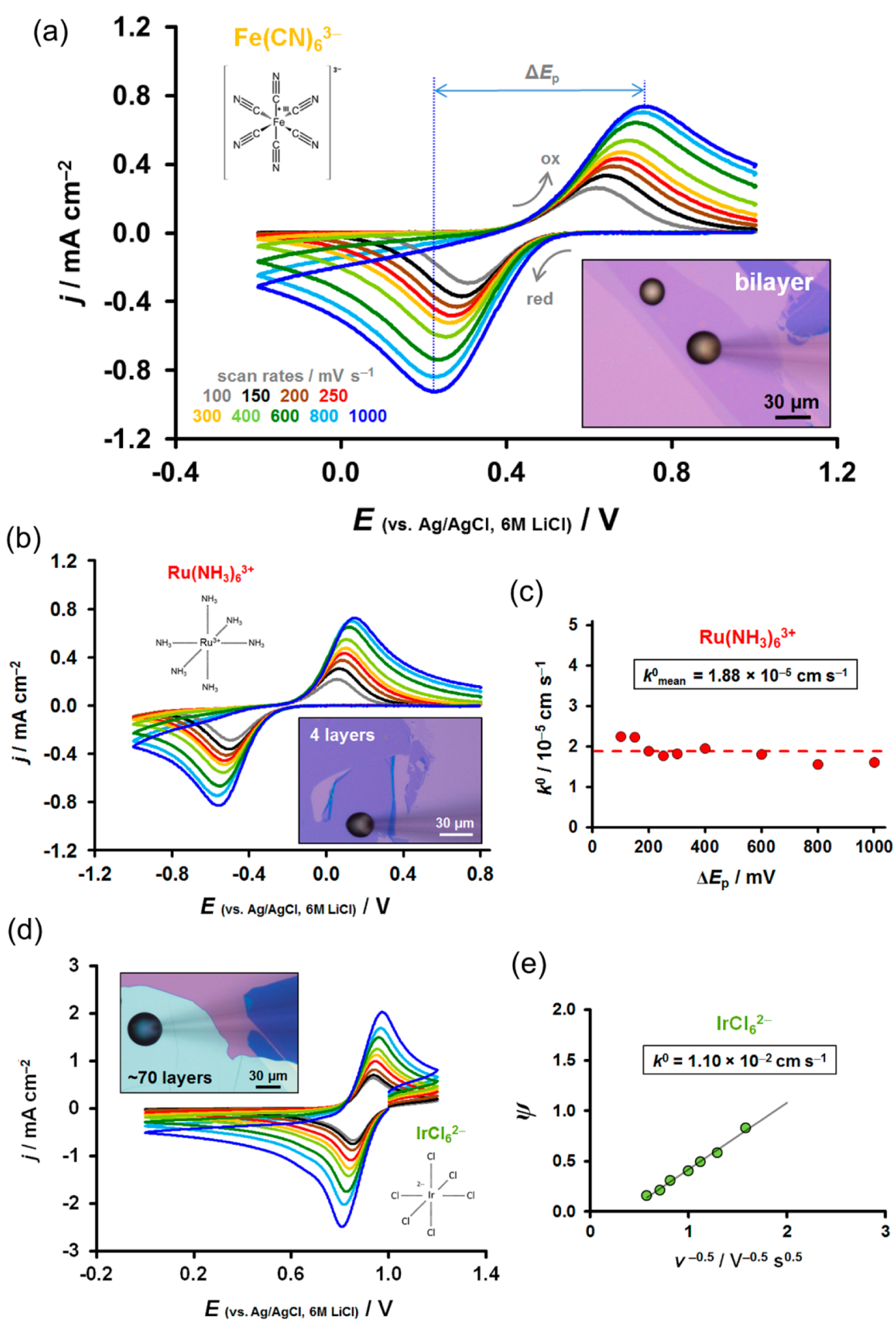

(e)

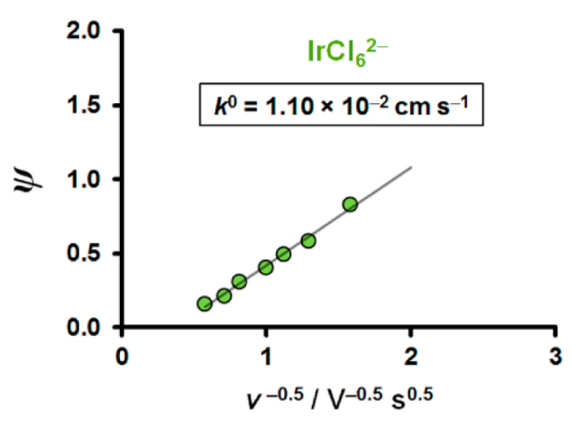

Figure 2. Cyclic voltammograms and associated kinetic analyses at graphene/graphite electrodes. (a) $\mathrm{CV}$ of $\mathrm{Fe}(\mathrm{CN})_{6}{ }^{3-/ 4-}$ on bilayer graphene, ( $b$ and d) show comparison of ET kinetics on 4-layer graphene using $\mathrm{Ru}\left(\mathrm{NH}_{3}\right)_{6}{ }^{3+/ 2+}$ and on $\sim 70$-layer thick graphite using $\mathrm{IrCl}_{6}{ }^{2-/ 3-}$. Corresponding Klingler-Kochi and Nicholson analyses and calculated ET rates $\left(k^{0}\right)$ are shown in (c) and (e), respectively. The insets in the bottom right of graphs (a), (b), and (d) show micrographs of the deposited droplets. The series of voltammetric curves were obtained starting from the fastest scan rate of $1000 \mathrm{mV} \mathrm{s}^{-1}$ (dark blue) down to the slowest scan rate of $100 \mathrm{mV} \mathrm{s}^{-1}$ (gray) for $\mathrm{Fe}(\mathrm{CN})_{6}{ }^{3-/ 4-}$ and $\mathrm{Ru}\left(\mathrm{NH}_{3}\right)_{6}{ }^{3+/ 2+}$ and $3000-250 \mathrm{mV} \mathrm{s}{ }^{-1}$ for $\mathrm{IrCl}_{6}{ }^{2-/ 3-}$. The potential was referenced against $\mathrm{Ag} / \mathrm{AgCl}$ wire in $6 \mathrm{M} \mathrm{LiCl}$, and held at the upper vertex potential for $10 \mathrm{~s}$ prior to the voltammetry $\left(1 \mathrm{~V}\right.$ for $\left.\mathrm{IrCl}_{6}{ }^{2-/ 3-}\right)$. Change of the initial direction of the potential sweep had no observable effect.

regime within small droplets. Hence, the applied scan rate was kept between the limits of 100 and $1000 \mathrm{mVs}^{-1}$, or 250 and $3000 \mathrm{mV} \mathrm{s}^{-1}$, corresponding to typical $\Delta E_{\mathrm{p}}$ ranges of $200-600$ and $300-900 \mathrm{mV}$, or $60-250 \mathrm{mV}$, for $\mathrm{Fe}(\mathrm{CN})_{6}{ }^{3-}$ and $\mathrm{Ru}\left(\mathrm{NH}_{3}\right)_{6}{ }^{3+}$, or $\mathrm{IrCl}_{6}{ }^{2-}$, respectively. For these reasons, diffusion coefficients of the redox 
mediators in $6 \mathrm{M} \mathrm{LiCl}$ (aq.) were determined independently, using a platinum disk macro-electrode with well-defined reversible ET behavior, as $1.84( \pm 0.19) \times$ $10^{-6} \mathrm{~cm}^{2} \mathrm{~s}^{-1}, 2.36( \pm 0.11) \times 10^{-6} \mathrm{~cm}^{2} \mathrm{~s}^{-1}, 2.27$ $( \pm 0.14) \times 10^{-6} \mathrm{~cm}^{2} \mathrm{~s}^{-1}$ for $\mathrm{Fe}(\mathrm{CN})_{6}{ }^{3-}, \mathrm{Ru}\left(\mathrm{NH}_{3}\right)_{6}{ }^{3+}$ and $\mathrm{IrCl}_{6}{ }^{2-}$, respectively (full details of analysis in Supporting Information).

For $\Delta E_{\mathrm{p}}<220 \mathrm{mV}$, the kinetic parameter $\psi$ was plotted as a function of the inverse square root of scan rate (all of $\mathrm{IrCl}_{6}{ }^{2-/ 3-}$ and some $\mathrm{Fe}(\mathrm{CN})_{6}{ }^{3-/ 4-}$ data). ${ }^{31,34}$ This dependence yields a linear gradient, which is analyzed using eq 2 and the heterogeneous ET rate, $k^{0}$, calculated as shown in Figure 2e. For $\Delta E_{\mathrm{p}}>220 \mathrm{mV}$, eq 3 was used to calculate individual $k^{0}$ for each scan rate and the arithmetic mean was obtained (all of $\mathrm{Ru}\left(\mathrm{NH}_{3}\right)_{6}{ }^{3+/ 2+}$ and most of $\mathrm{Fe}(\mathrm{CN})_{6}^{3-/ 4-}$ data) as shown in Figure 2c. The above analysis was performed for each individual droplet, i.e. for a microscopic surface of area ca. 300-3000 $\mu \mathrm{m}^{2}$, and, except for the nearreversible kinetics of $\mathrm{IrCl}_{6}^{2-/ 3-}$ reduction/oxidation, the kinetics were found to be independent of the droplet/graphene area (full details in Supporting Information, Figure S8). A comparison of the CVs reveals wider $\Delta E_{\mathrm{p}}$, hence slower kinetics, for $\mathrm{Ru}\left(\mathrm{NH}_{3}\right)_{6}{ }^{3+/ 2+}$ and $\mathrm{Fe}(\mathrm{CN})_{6}{ }^{3-14-}$ reduction/oxidation (Figure 2a,b) and smaller $\Delta E_{\mathrm{p}}$, hence faster kinetics, for $\mathrm{IrCl}_{6}{ }^{2-13-}$ reduction/oxidation (Figure $2 \mathrm{~d}$ ).

Dependence of Electron Transfer Kinetics on the Number of Graphene Layers. This work was motivated by the lack of literature consensus on the effect of the number of graphene layers on ET kinetics of a pristine basal plane. However, during the initial investigation, it was found that the ET rate often varied significantly across the surface of the same flake and the resulting plot of the averaged ET rate vs, number of graphene layers was very scattered. On these grounds, eight or more individual droplet measurements were carried out on several flakes of the same thickness (or similar thickness for $>20$ layers) and the arithmetic mean of $k^{0}$ obtained, with a total of 435 individual droplets analyzed across the surface of 69 individual flakes. The $k^{0}$ values for $\mathrm{Fe}(\mathrm{CN})_{6}{ }^{3-/ 4-}$, $\mathrm{Ru}\left(\mathrm{NH}_{3}\right)_{6}{ }^{3+/ 2+}$, and $\mathrm{IrCl}_{6}{ }^{2-/ 3-}$ reduction/oxidation on flakes of varied thickness between 1 and ca. 1000 graphene layers are shown in Figure 3, panels a, b, and c, respectively. It is apparent that despite the large statistical sample there is not a strong correlation between the flake thickness and the basal plane ET kinetics, although the variation is more pronounced for flakes with thickness less than 20 graphene layers. The $k^{0}$ values are scattered around the arithmetic mean of the whole data set, which is indicated by the colored dashed line. For $\mathrm{Fe}(\mathrm{CN})_{6}{ }^{3-/ 4-}$, the mean ET rates range from $0.13( \pm 0.02) \times 10^{-3}$ $\mathrm{cm} \mathrm{s}^{-1}$ for the bilayer to $2.09( \pm 1.27) \times 10^{-3} \mathrm{~cm} \mathrm{~s}^{-1}$ for 7 layers, with an overall mean value of $0.90( \pm 0.13) \times$ $10^{-3} \mathrm{~cm} \mathrm{~s}{ }^{-1}$. Ru $\left(\mathrm{NH}_{3}\right)_{6}^{3+/ 2+}$ kinetics range from $0.11( \pm 0.12) \times 10^{-4} \mathrm{~cm} \mathrm{~s}^{-1}$ for $20-30$ layers to
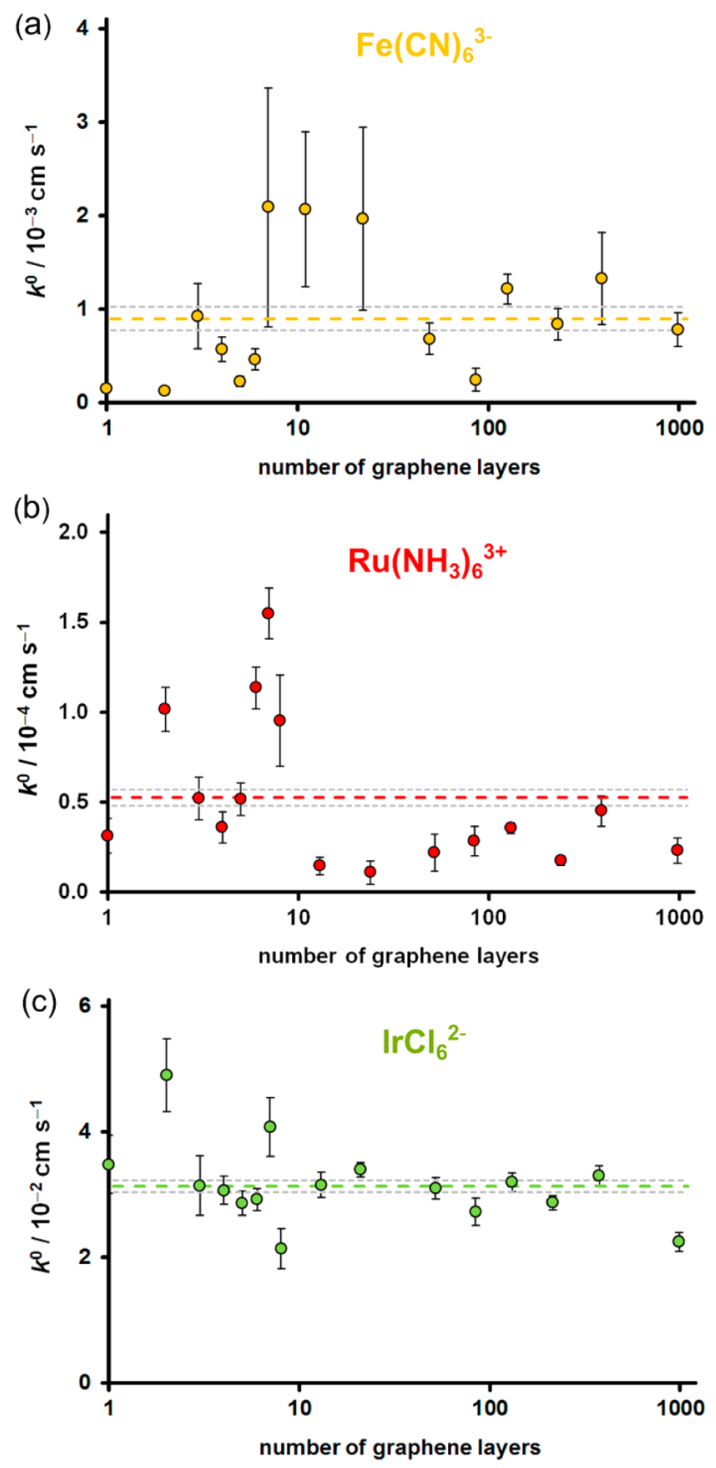

Figure 3. Heterogeneous ET rate, $k^{0}$, between the aqueousbased redox mediator and mechanically exfoliated graphite flakes of varied thicknesses. The averaged ET rates of reduction/oxidation of (a) $\mathrm{Fe}(\mathrm{CN})_{6}^{3-/ 4-}$, (b) $\mathrm{Ru}\left(\mathrm{NH}_{3}\right)_{6}{ }^{3+/ 2+}$ and $\mathrm{IrCl}_{6}{ }^{2-/ 3-}$ reduction/oxidation are plotted as a function of the number of graphene layers. Each point on the graph is an arithmetic mean of at least 8 (thick flakes $>7$ layers) or 12 (thin flakes $\leq 7$ layers) individual droplet measurements on a pristine basal plane surface of one or more flakes of a given thickness. The error bars are standard deviations of the mean. The number of individual droplets included in the analysis was 145,146 , and 144 for $\mathrm{Fe}(\mathrm{CN})_{6}{ }^{3-14-}, \mathrm{Ru}\left(\mathrm{NH}_{3}\right)_{6}{ }^{3+/ 2+}$, and $\mathrm{IrCl}_{6}{ }^{2-13-}$, respectively. In total, 69 individual crystal surfaces were used for the analysis. Note that the graphs are shown on a semilogarithmic scale.

$1.55( \pm 0.14) \times 10^{-4} \mathrm{~cm} \mathrm{~s}^{-1}$ for 7 layers and an overall mean value of $0.53( \pm 0.04) \times 10^{-4} \mathrm{~cm} \mathrm{~s}^{-1}$. Finally, $\mathrm{IrCl}_{6}^{2-/ 3-}$ reduction/oxidation kinetics range from 2.14 $( \pm 0.32) \times 10^{-2} \mathrm{~cm} \mathrm{~s}^{-1}$ for $8-9$ layers to $4.91( \pm 0.58) \times$ $10^{-2} \mathrm{~cm} \mathrm{~s}^{-1}$ for a bilayer and an overall mean value of $3.13( \pm 0.10) \times 10^{-2} \mathrm{~cm} \mathrm{~s}^{-1}$. The $\mathrm{IrCl}_{6}{ }^{2-/ 3-}$ kinetics recorded on multilayer graphene flakes are on the same order of magnitude as our previous work on flakes on a polymer substrate. ${ }^{19}$ 
The effects of uncompensated resistance due to flake thickness/ohmic contacts, which would affect $\Delta E_{\mathrm{p}}$ and hence the calculated $k^{0}$, were ruled out (Figures S11-S14, Supporting Information).

The variation of the kinetics across the surface of the same graphene crystal is the dominating factor, which increases the uncertainty and masks any underlying trends in the change of kinetics with flake thickness. Table 1 summarizes the ET kinetics data obtained for all three redox mediators.

Surface Sensitivity to Contaminants. Significant variation of the ET rate across different surface sites of the same flake is also reflected in the large relative errors of some of the data in Table 1 (especially for $\mathrm{Fe}(\mathrm{CN})_{6}{ }^{3-/ 4-}$ ). This confirms that, beyond any intrinsic dependence flake thickness, the kinetics also reflect local surface conditions, i.e., are spatially dependent. Unfortunately, these two factors are difficult to separate experimentally. Sensitivity of graphite surfaces to exposure to the atmosphere and therefore oxygen, moisture and other contaminants, has been previously reported to affect electrode kinetics measurements. ${ }^{35}$ For example, Patel et al. performed an extensive study of reduction/oxidation of $\mathrm{Fe}(\mathrm{CN})_{6}{ }^{3-/ 4-}$ and $\mathrm{Ru}\left(\mathrm{NH}_{3}\right)_{6}{ }^{3+/ 2+}$ on highly oriented pyrolytic graphite (HOPG), demonstrating that both atmospheric exposure of the HOPG and prolonged voltammetric measurement significantly diminish the ET kinetics, indicating surface poisoning and passivation. ${ }^{35}$ Indeed, other recent studies by the same group confirmed that the pristine basal plane of freshly cleaved HOPG actually has remarkably high ET activity, ${ }^{36,37}$ in contrast to previous reports. ${ }^{38,39}$
We observe a significant difference in kinetics between freshly cleaved and aged surfaces of natural graphite, exposed to the ambient environment for days or weeks, in accordance with results reported by Patel et $a .^{35}$ The tip of the micropipette was used to cleave layers of graphite from the edge, forcing the liquid into contact with the freshly exposed surface, without exposure to the atmosphere. The CVs recorded immediately after the in situ cleavage of graphite (original thickness of $313 \mathrm{~nm}, \sim 933$ graphene layers) revealed significantly reduced $\Delta E_{\mathrm{p}}$ of $c a$. 80-130 $\mathrm{mV}$ for the applied scan rate range, and $k^{0}$, averaged for three different cleaved areas, was determined as $4.73( \pm 0.39) \times 10^{-3} \mathrm{~cm} \mathrm{~s}^{-1}$, indicating nearreversible kinetic behavior, close to 2 orders of magnitude faster than the overall arithmetic mean for all the atmosphere-aged basal planes (see Table 1). It is evident that $\mathrm{Ru}\left(\mathrm{NH}_{3}\right)_{6}{ }^{3+/ 2+}$ reduction/oxidation exhibits much faster kinetics on the freshly cleaved surface than on surfaces exposed to the ambient environment. The microcleaved area includes the edges of graphite, so measurement of a droplet deposited such that it covered the edge plane was carried out as a control. This did not reveal a significant change in the ET rate, which confirms that the observed difference is purely due to the inherent difference between freshly cleaved and aged surfaces of graphite (Figure S15, Supporting Information). The in situ cleavage was also attempted on thinner flakes; however, the method fails for thicknesses below ca. $20 \mathrm{~nm}$ as it is difficult to avoid tipinduced damage of the flakes. The rapid deterioration

TABLE 1. Heterogeneous ET Rate, $k^{0}$, of Reduction/Oxidation of Three Redox Mediators on Natural Graphene/Graphite Electrodes of Varied Thicknesses ${ }^{a}$

\begin{tabular}{|c|c|c|c|c|c|c|}
\hline \multirow[b]{2}{*}{ no. of layers } & \multicolumn{2}{|c|}{$\mathrm{Fe}(\mathrm{CN})_{6}{ }^{3-/ 4-}$} & \multicolumn{2}{|c|}{$\mathrm{Ru}\left(\mathrm{NH}_{3}\right)_{6}{ }^{3+/ 2+}$} & \multicolumn{2}{|c|}{$\operatorname{IrCl}_{6}^{2-/ 3-}$} \\
\hline & $k^{0} / 10^{-3} \mathrm{~cm} \mathrm{~s}^{-1}$ & $\Delta / k^{0}$ & $k^{0} / 10^{-4} \mathrm{~cm} \mathrm{~s}^{-1}$ & $\Delta / k^{0}$ & $k^{0} / 10^{-2} \mathrm{~cm} \mathrm{~s}^{-2}$ & $\Delta / k^{0}$ \\
\hline 1 & $0.15 \pm 0.02$ & 0.12 & $0.31 \pm 0.10$ & 0.31 & $3.48 \pm 0.47$ & 0.13 \\
\hline 2 & $0.13 \pm 0.02$ & 0.16 & $1.02 \pm 0.12$ & 0.12 & $4.91 \pm 0.58$ & 0.12 \\
\hline 3 & $0.93 \pm 0.35$ & 0.38 & $0.52 \pm 0.12$ & 0.23 & $3.15 \pm 0.48$ & 0.15 \\
\hline 4 & $0.57 \pm 0.13$ & 0.22 & $0.36 \pm 0.09$ & 0.24 & $3.07 \pm 0.22$ & 0.07 \\
\hline 5 & $0.23 \pm 0.05$ & 0.23 & $0.52 \pm 0.09$ & 0.17 & $2.87 \pm 0.19$ & 0.07 \\
\hline 6 & $0.46 \pm 0.11$ & 0.25 & $1.14 \pm 0.12$ & 0.10 & $2.93 \pm 0.17$ & 0.06 \\
\hline 7 & $2.09 \pm 1.27$ & 0.61 & $1.55 \pm 0.14$ & 0.09 & $4.08 \pm 0.47$ & 0.11 \\
\hline $8-9$ & - & - & $0.95 \pm 0.25$ & 0.27 & $2.14 \pm 0.32$ & 0.15 \\
\hline $11-13$ & $2.07 \pm 0.83$ & 0.40 & $0.15 \pm 0.05$ & 0.34 & $3.16 \pm 0.20$ & 0.06 \\
\hline $20-30$ & $1.97 \pm 0.98$ & 0.50 & $0.11 \pm 0.06$ & 0.59 & $3.40 \pm 0.11$ & 0.03 \\
\hline $50-60$ & $0.68 \pm 0.17$ & 0.25 & $0.22 \pm 0.10$ & 0.47 & $3.11 \pm 0.17$ & 0.05 \\
\hline $80-90$ & $0.24 \pm 0.12$ & 0.51 & $0.28 \pm 0.08$ & 0.29 & $2.73 \pm 0.22$ & 0.08 \\
\hline $100-130$ & $1.22 \pm 0.16$ & 0.13 & $0.36 \pm 0.03$ & 0.09 & $3.20 \pm 0.15$ & 0.05 \\
\hline $220-250$ & $0.84 \pm 0.17$ & 0.20 & $0.17 \pm 0.03$ & 0.16 & $2.87 \pm 0.12$ & 0.04 \\
\hline $300-500$ & $1.33 \pm 0.49$ & 0.37 & $0.45 \pm 0.08$ & 0.19 & $3.30 \pm 0.15$ & 0.05 \\
\hline$>1000$ & $0.78 \pm 0.18$ & 0.23 & $0.23 \pm 0.07$ & 0.31 & $2.25 \pm 0.15$ & 0.07 \\
\hline mean & $0.90 \pm 0.13$ & 0.30 & $0.53 \pm 0.04$ & 0.25 & $3.13 \pm 0.10$ & 0.08 \\
\hline cleaved & - & - & $47.3 \pm 3.9$ & 0.08 & - & - \\
\hline
\end{tabular}

${ }^{a}$ The errors are standard deviations of 8 or more measurements at various locations on flakes of the same thickness. The number of graphene layers was determined using a combination of optical microscopy, Raman spectroscopy and atomic force microscopy (AFM) as described in the Methods. The variation of the ET kinetics on flakes of the same thickness is reflected in the relative error, $\Delta / k^{0}$. Arithmetic means and their standard deviations are also listed at the bottom of table. 
of the surface upon exposure to air is likely to occur within minutes or hours after exfoliation as suggested by other groups. ${ }^{35,40}$

The findings above lead to several conclusions about the ET kinetics on mono- and multilayer graphene surface. The data supports an increasing amount of evidence in the literature, ${ }^{17,19,30,35-37}$ that the basal plane of graphitic surfaces is active with respect to electron transfer. Only pristine basal planes, whose defect-free nature was confirmed by the absence of D-peak in Raman spectrum (see Methods), were chosen for the droplet deposition. Nevertheless, the optical resolution of this method is $\sim 1 \mu \mathrm{m}$, meaning that nanoscale defects could remain undetected and affect the ET measurement. In such a scenario, the large variation of the kinetics across the surface of the same flakes could be explained by random distribution of nanoscale defects increasing the ET activity, in accordance with the traditional view of graphite electrochemistry. ${ }^{14,15}$ Recent studies on the mobility of atoms on graphene surfaces show that not only does the graphene lattice undergo a self-repair mechanism of its basal plane, but also metallic impurities tend to migrate toward the edge planes and defect sites, where they are stabilized. ${ }^{41,42}$ This insight plays a significant role in the electrochemistry of graphene and contributes to the ongoing debate regarding edge plane/defect vs basal plane ET activity, as most metals have very fast ET kinetics toward most redox mediators. ${ }^{43}$ This was also demonstrated by Ritzert et al., who observed an increased ET rate upon adsorption of kinetic-enhancing redox-active species on $c a$. $1 / 100$ of the graphene surface, confirming that even small amounts of impurities play a significant role in electrode kinetics. ${ }^{29}$ Furthermore, formation of electron and hole "puddles" was observed and attributed to either warping of the suspended graphene sheets ${ }^{44}$ or doping induced by the underlying substrate. ${ }^{45}$ These imperfections will naturally lead to nano- or microscale inhomogeneity of the graphene surface.

Another significant observation is the acceleration of kinetics on freshly cleaved graphite. We found that the surface conditions and the sample exposure to the ambient environment significantly perturb any inherent relationship between ET activity and the flake thickness. This is most likely due to a chemical modification of the graphene/graphite surface due to reaction with oxygen, water or other chemicals present in the air and/or adsorption of contaminant molecules/ functional groups on the surface. ${ }^{15,46-48} \mathrm{X}$-ray photoelectron spectroscopy (XPS) shown in Figure 4 and energy-dispersive X-ray spectroscopy (EDX) (Figures S18 and S19, Supporting Information) were performed on both atmosphere-aged and freshly cleaved graphite surfaces.

The spectra are averaged over 5 different surface sites to obtained maximum sensitivity to trace impurity elements. The full quantification of the spectroscopic data across the 5 different surface sites is found in Table 2. Analysis of the averaged spectra revealed no substantial variation in the elemental composition. Both aged and cleaved surfaces contain ca. 92.8-93.2\% carbon, $4.4-5.0 \%$ oxygen, $0.8-1.1 \%$ of fluorine and a total of $0.7-2.0 \%$ of other impurities, including $\mathrm{N}, \mathrm{Na}, \mathrm{Al}, \mathrm{Si}, \mathrm{S}, \mathrm{K}, \mathrm{Ca}$, and $\mathrm{Ni}$ (atomic percentages). The cleaved sample, however, exhibits significant site-to-site variation, particularly in carbon and oxygen concentration, in comparison to the aged

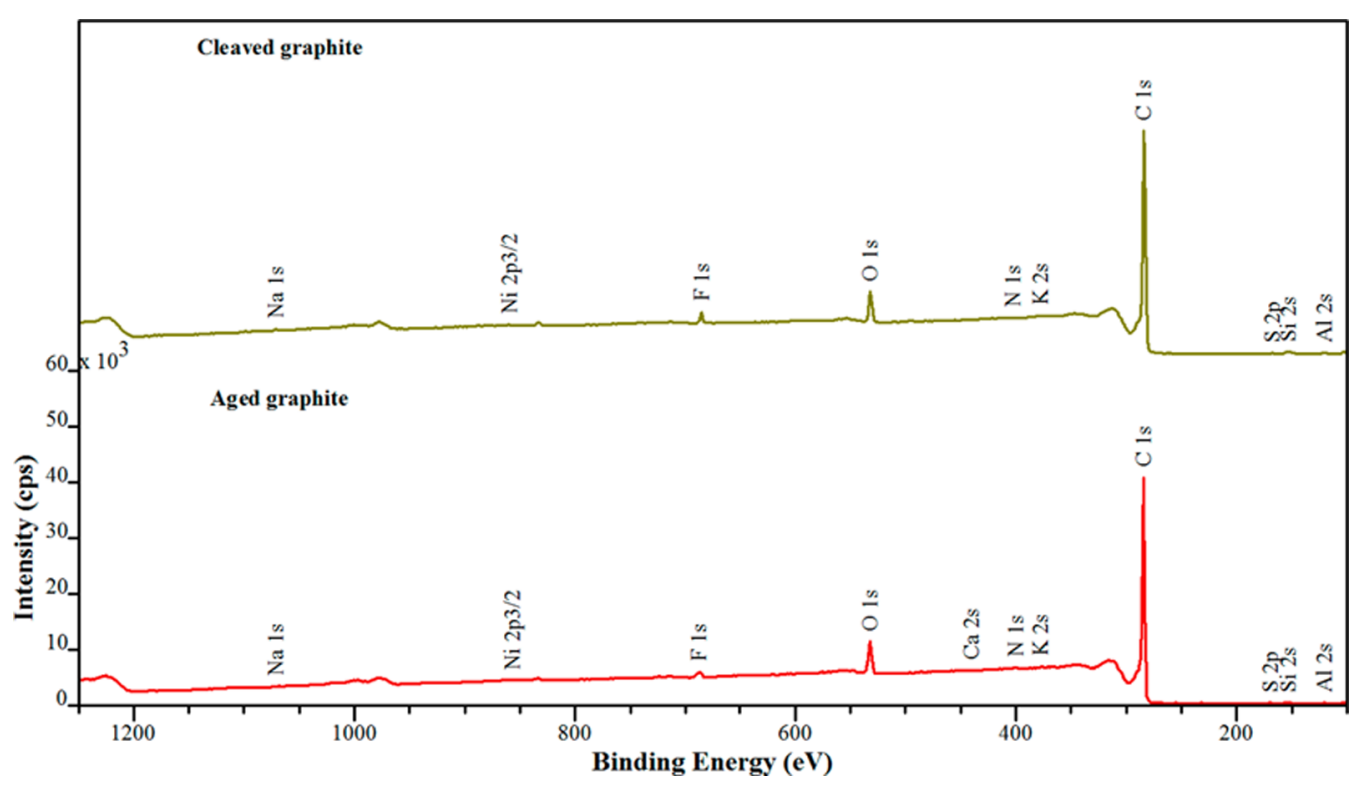

Figure 4. XPS survey spectra of atmosphere-aged ( $>1$ month) graphite surface (top green) and pristine graphite surface cleaved immediately prior the XPS measurement (bottom red). Both spectra show data averaged from 5 different sites on the surface (spot size of $400 \mu \mathrm{m}^{2}$ ). The quantitative elemental analysis is given in Table 2 . 
TABLE 2. Quantitative Analysis of the XPS Spectra Obtained at Five Different Surface Sites on Aged and Cleaved Graphite Samples

\begin{tabular}{|c|c|c|c|c|}
\hline \multirow[b]{2}{*}{ element } & \multicolumn{2}{|c|}{ surface site variation/At $\%$} & \multicolumn{2}{|c|}{ mean $/ \mathrm{At} \%$} \\
\hline & aged & cleaved & aged & cleaved \\
\hline$C$ & $88.54-94.08$ & $85.76-97.42$ & 92.84 & 93.17 \\
\hline $\mathrm{N}$ & $0.09-0.56$ & $0.00-0.33$ & 0.37 & 0.12 \\
\hline 0 & $4.31-8.06$ & $1.35-12.10$ & 4.98 & 4.39 \\
\hline $\mathrm{F}$ & $0.23-1.55$ & $0.45-1.87$ & 0.78 & 1.09 \\
\hline $\mathrm{Na}$ & $<0.01$ & $0.01-0.51$ & 0.01 & 0.08 \\
\hline $\mathrm{Al}$ & $0.07-0.49$ & $0.01-0.79$ & 0.16 & 0.34 \\
\hline $\mathrm{Si}$ & $0.39-1.60$ & $0.51-1.51$ & 0.65 & 0.72 \\
\hline$S$ & $0.14-0.24$ & $0.00-0.10$ & 0.14 & 0.03 \\
\hline K & $0.00-0.13$ & $0.00-0.10$ & 0.04 & 0.04 \\
\hline $\mathrm{Ca}$ & $0.00-1.64$ & $<0.01$ & 0.03 & 0.00 \\
\hline $\mathrm{Fe}$ & $<0.01$ & $<0.01$ & 0.00 & 0.00 \\
\hline $\mathrm{Ni}$ & $0.00-0.01$ & $0.00-0.06$ & 0.01 & 0.03 \\
\hline
\end{tabular}

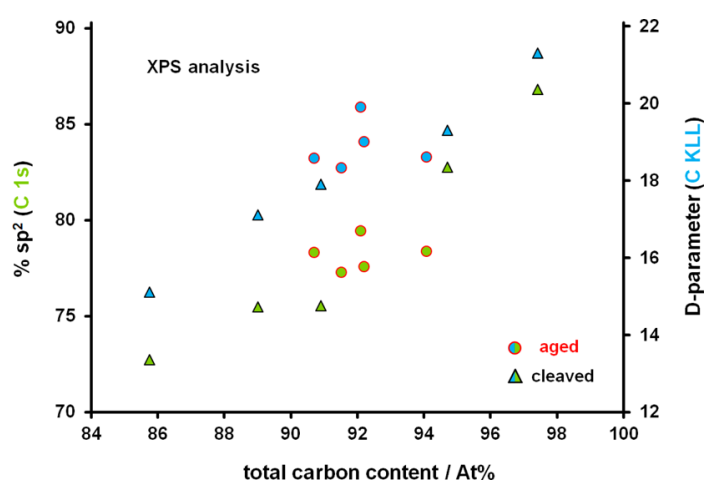

Figure 5. Effect of impurities on hybridization and functionalization of carbon atoms expressed by XPS analysis of both atmosphere-aged (circles) and cleaved (triangles) graphite surface. The extent of carbon $\mathrm{sp}^{2}$ hybridization, determined from C 1s peak (green) and Auger peak (D-parameter, blue), is proportional to the total carbon content (XPS survey quantification).

sample. We attributed this to high reactivity of the freshly cleaved graphite and enhanced ability of the pristine surface to adsorb organic and inorganic molecules (Table 2), whereas the prolonged exposure of the aged graphite to the ambient environment yields similar carbon/oxygen ratio at different surface sites indicating uniformity of the surface modification. Furthermore, the extent of $\mathrm{sp}^{2}$ hybridization of carbon atoms in both samples is directly correlated with the overall carbon concentration (Figure 5), which most likely points toward formation of an organic, $\mathrm{sp}^{3}$-rich adsorbent layer, or suggests that the contaminants react with carbon and modify the graphite lattice (full details of XPS and EDX analyses are found in Supporting Information).

Comparison of the Kinetics for $\mathrm{Fe}(\mathrm{CN})_{6}{ }^{3-/ 4-}, \mathrm{Ru}\left(\mathrm{NH}_{3}\right)_{6}{ }^{3+/ 2+}$, and $\mathrm{IrCl}_{6}{ }^{2-/ 3-}$. The droplet-to-droplet variation of ET rate on flakes of the same thickness, expressed in the arithmetic mean of the relative errors $\left(\Delta / k^{0}\right)$ in Table 1, is most pronounced for $\mathrm{Fe}(\mathrm{CN})_{6}{ }^{3-/ 4-}$, slightly less for
$\mathrm{Ru}\left(\mathrm{NH}_{3}\right)_{6}{ }^{3+/ 2+}$, and the least for $\mathrm{IrCl}_{6}{ }^{2-/ 3-}$. The same trend is observed for a difference between the maximum and minimum averaged and absolute kinetics for the three mediators. The maximum difference in averaged kinetics (from Table 1) is ca. 16-, 14-, and 2 -fold, and the maximum difference in absolute kinetics (from individual droplet measurements) is ca. 3 orders of magnitude for both $\mathrm{Fe}(\mathrm{CN})_{6}{ }^{3-/ 4-}$ and $\mathrm{Ru}$ $\left(\mathrm{NH}_{3}\right)_{6}{ }^{3+/ 2+}$ and only ca. 8-fold for $\mathrm{IrCl}_{6}{ }^{2-/ 3-}$. This is consistent with $\mathrm{Fe}(\mathrm{CN})_{6}{ }^{3-}$ being an inner-sphere redox mediator with inherent sensitivity to surface states, ${ }^{15}$ and indeed, previously reported $k^{0}$ values for this mediator on graphene vary significantly. ${ }^{17,19,20,24,27-29}$ In an idealized scenario, the observed kinetics of a genuine outer-sphere mediator, which maintains its original coordination sphere during the ET process, ${ }^{14,15,34}$ would only depend on the density of states (DOS) of the electrode material and would therefore be less sensitive to mild surface contamination. This behavior is, to an extent, observed for $\mathrm{IrCl}_{6}{ }^{2-}$ as reflected in the error analysis above. Furthermore, the fact that the variation in ET kinetics of the two outer-sphere mediators $\left(\mathrm{Ru}\left(\mathrm{NH}_{3}\right)_{6}{ }^{3+}\right.$ and $\left.\mathrm{IrCl}_{6}{ }^{2-}\right)$ is most pronounced for the thin flakes ( $<20$ layers) raises a question as to whether this is related to local impurity-induced changes in the DOS, which should be most pronounced in mono- and few-layer graphene.

Interestingly, the absolute value of $k^{0}$ for $\mathrm{Ru}\left(\mathrm{NH}_{3}\right)_{6}{ }^{3+}$ reduction/oxidation is much lower than reported literature values, ${ }^{15,29,35,37,49}$ contrary to the common conception of $\mathrm{Ru}\left(\mathrm{NH}_{3}\right)_{6}{ }^{3+}$ as an outer-sphere mediator. Although, the number of electrochemical studies carried out on natural graphite is very limited, in contrast to the well-studied kinetics on other carbon electrodes such as glassy carbon and HOPG, the slow kinetics observed in this work is not the sole exception to the fast kinetics generally assumed for this mediator: $k^{0}$ of ca. $10^{-5}$ to $10^{-4} \mathrm{~cm} \mathrm{~s}^{-1}$ were reported on the basal plane of HOPG surface. ${ }^{36}$ To provide a direct comparison with other materials, we employed a microdroplet technique to measure $\mathrm{Ru}\left(\mathrm{NH}_{3}\right)_{6}{ }^{3+/ 2+}$ ET kinetics on platinum, gold and HOPG electrodes. Comparison of voltammetry and kinetics on these surfaces in Figure 6, panels $a$ and $b$, respectively, shows that the kinetics on both cleaved HOPG and natural graphite reach values close to those of unpolished metal surfaces (Pt and $\mathrm{Au}$ ). The difference between cleaved and aged surfaces, however, seems to be less pronounced for HOPG than natural graphite, and furthermore, aged HOPG exhibits kinetics almost 1 order of magnitude faster than that of aged natural graphite. Slow $\mathrm{Ru}\left(\mathrm{NH}_{3}\right)_{6}{ }^{3+/ 2+}$ kinetics observed on natural ME graphite/graphene cannot solely be explained via the intrinsically low DOS in these materials because of the relatively facile kinetics of the other two mediators. The different behavior with $\mathrm{Ru}\left(\mathrm{NH}_{3}\right)_{6}{ }^{3+/ 2+}$ is therefore attributed to fundamental 

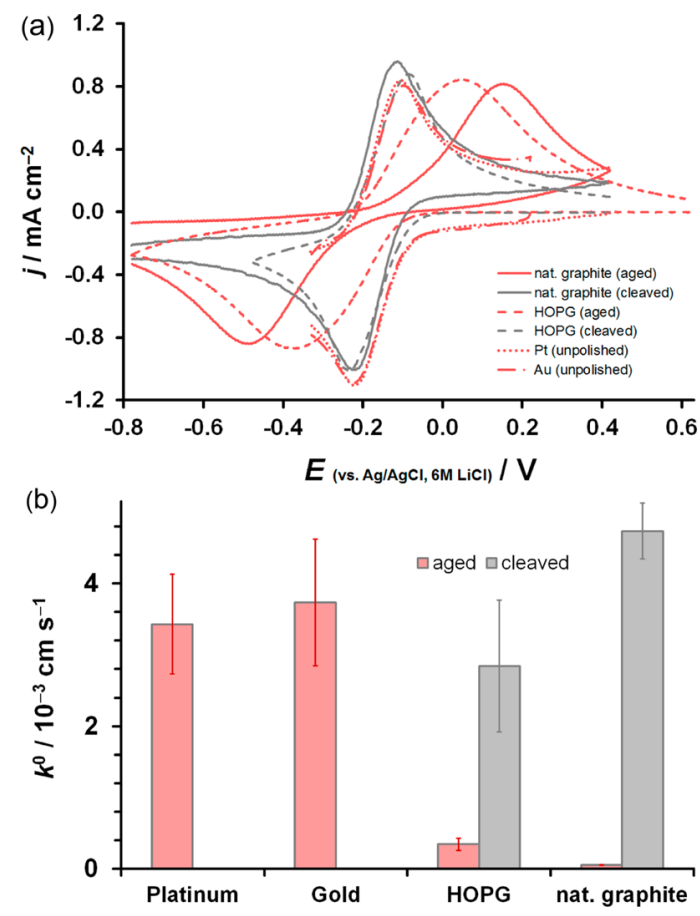

Figure 6. (a) Cyclic voltammograms recorded on natural graphite (solid curve), HOPG (dashed curve), platinum (dotted curve), and gold (dash-dot curve), and (b) corresponding ET kinetics obtained as an arithmetic mean of three independent measurements. Data in red and gray correspond to aged and cleaved surfaces, respectively. Mechanically polished metal surfaces exhibited almost reversible kinetics $\left(>10^{-2} \mathrm{~cm} \mathrm{~s}^{-1}\right)$ with peak separation below $65 \mathrm{mV}$ at $1 \mathrm{~V} \mathrm{~s}^{-1}$.

differences between natural graphite/graphene and other carbon materials and misclassification of $\mathrm{Ru}\left(\mathrm{NH}_{3}\right)_{6}{ }^{3+}$ as a "true" outer-sphere mediator. This is also supported by the two-orders of magnitude difference between the freshly cleaved and aged surface described above. Furthermore, adsorbed organic molecules and/or a functionalized surface would alter the DOS at the electrode surface and, in the case of a sufficiently thick layer of modified surface, alter the measured kinetics of an outer-sphere mediator.
Ongoing work is aimed at producing a full understanding of the fundamental electrochemical properties of graphene/graphite and elucidation of the inherent relationship between ET kinetics and thickness, without interference from surface functionalization/ contamination, which requires very careful surface preparation/treatment control.

\section{CONCLUSIONS}

The basal plane of graphene/graphite is found to be electrochemically active, despite some contradictory findings in previous literature: both edge and basal planes will have significant roles in the performance of future graphene-based electrode materials. The electron transfer kinetics between a substrate-bound natural graphene/graphite and three different redox mediators, $\mathrm{Fe}(\mathrm{CN})_{6}{ }^{3-}$, $\mathrm{Ru}\left(\mathrm{NH}_{3}\right)_{6}{ }^{3+}$, and $\mathrm{IrCl}_{6}{ }^{2-}$ is dominated by the local microscopic condition of the flake surface, a fact largely neglected in electrochemical studies of graphene. A significant variation of the measured ET rate across the surface of a single basal plane crystal is observed, which largely obscures any inherent correlations between the kinetics and number of graphene layers. This is attributed to exposure of the graphene/graphite surface to ambient environment and subsequent adsorption of contaminants and/or functionalization of the surface. Most importantly, the $\mathrm{Ru}\left(\mathrm{NH}_{3}\right)_{6}{ }^{3+}$ couple on the in situ cleaved surface exhibits kinetics several orders of magnitude faster than that of an aged surface. These considerations are crucial for full exploitation of the large specific surface area and transparency of graphene electrodes while maintaining superior electrochemical performance. It is clear that further investigations in this area are desirable and that high surface quality control is necessary to separate the effects of contamination and the graphene/graphite thickness on electrochemical activity. Crucially, future studies should focus on distinguishing spatial variations in kinetics from the temporal ones.

\section{METHODS}

Chemicals. Acetone ( $\geq 99.0 \%)$, ethanol $(\geq 99.0 \%)$, potassium ferricyanide(III) (99+\%), hexaammineruthenium(III) chloride (98\%), ammonium hexachloroiridate(IV) (99.99\%), lithium chloride $(99 \%)$, and potassium chloride $(99 \%)$ were purchased from Sigma-Aldrich, U.K. Methyl isobutyl ketone (MIBK, 99.0+\%) and isopropyl alcohol (IPA, 99.5\%) were obtained from Fisher Scientific UK Ltd. All chemicals were used as received and aqueous solutions prepared using deionized water $(18.2 \mathrm{M} \Omega \mathrm{cm}$, Milli-Q Direct 8, Merck Millipore, Nillerica, MA).

Experimental Setup. A photograph and a detailed schematic of the experimental setup are shown in Figure 1, panels $a$ and $b$, respectively. The solution-filled borosilicate micropipette with a tip of ca. $1 \mu \mathrm{m}$ internal diameter (Figure S1, Supporting Information), was connected to a MX7630 motorized micromanipulator with MC 1000e motion controller (both Siskiyou, $\mathrm{OR})$, providing motion control in horizontal and vertical plane $\left(5-2000 \mu \mathrm{m} \mathrm{s}^{-1}\right)$ and visualized using either a GXML3030 optical microscope $(200 \times$ magnification) equipped with a GXCAM-9 CCD camera (both GT Vision Ltd., U.K.) or Nikon Eclipse LV100ND optical microscope with a DS-Fi2 U3 CCD camera (both Nikon Metrology, UK, Ltd.).

A pair of reference and counter electrodes was embedded in the micropipette. The $\mathrm{Ag} / \mathrm{AgCl}$ reference electrode (RE in Figure $1 \mathrm{~b}$ ) was made by oxidation of a partially exposed PTFE coated silver wire $(99.99 \%, 0.15 \mathrm{~mm}$ diameter) in $0.1 \mathrm{M} \mathrm{KCl}$ and the counter electrode (CE in Figure $1 \mathrm{~b}$ ) was made from platinum wire (99.99\%, $0.1 \mathrm{~mm}$ diameter). Graphene/graphite flake working electrodes (WE in Figure 1b), visualized using a SMZ-168 stereomicroscope (Motic GmbH, Germany), were connected to a copper wire (99.9\%, $0.15 \mathrm{~mm}$ diameter) with a silver epoxy (RS Components Ltd., UK). SPI-1 grade HOPG (SPI Supplies Inc., West Chester, PA) and platinum and gold foils (both 99.99\%) were connected the same way. All metals were purchased from Advent Research Materials, U.K. All the measurements were 
(a)

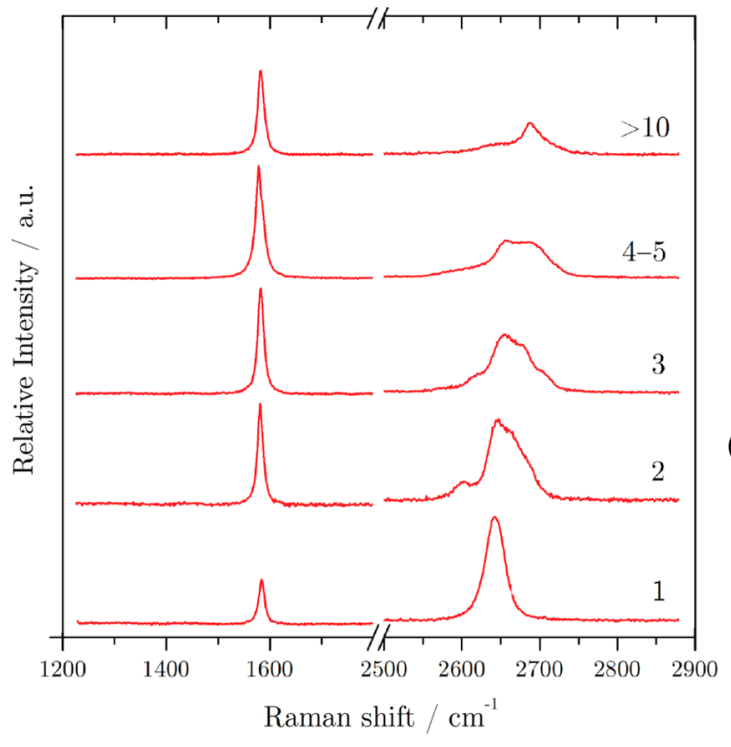

(b)

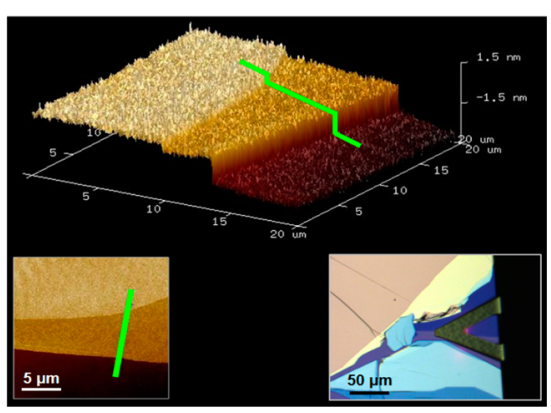

(c)

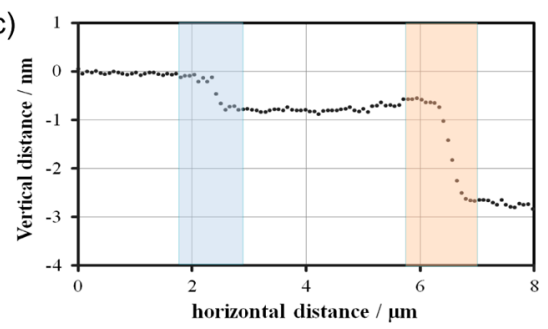

Figure 7. (a) Raman spectra of the mono-, bi-, tri-, tetra/penta-, and multilayer graphene flakes, bottom to top, respectively (each spectrum is shown on a different intensity scale for the purpose of clarity). (b) 3D and 2D AFM scans (top and bottomleft, respectively) of a ca. 4/5-layer thick graphene flake with another monolayer on top, inset (bottom-right) shows the optical image of the scanned area, (c) cross-section of the same flake, indicated by green lines in (b).

carried out at times longer than $24 \mathrm{~h}$ after exfoliation (minimum time needed for the silver epoxy to set). Comparison of the ET activity of the same flake within a range of $24 \mathrm{~h}$ up to 1 month after exfoliation revealed no systematic changes in kinetics, which could be attributed to the varied time after exfoliation. The electrochemical cell, which was enclosed in a Faraday cage and controlled by a PGSTAT302N potentiostat (Metrohm Autolab B.V., The Netherlands), can be described as follows:

\section{$\mathrm{Ag}(\mathrm{s})|\mathrm{AgCl}(\mathrm{s})| 3 \mathrm{mM} \mathrm{X}$ in $6 \mathrm{M} \mathrm{LiCl(aq)|graphene(s)}$}

where $\mathrm{X}$ is $\mathrm{K}_{3} \mathrm{Fe}(\mathrm{CN})_{6}, \mathrm{Ru}\left(\mathrm{NH}_{3}\right)_{6} \mathrm{Cl}_{3}$, or $\left(\mathrm{NH}_{4}\right)_{2} \mathrm{IrCl}_{6}$. The reference electrode potential (Ag/AgCl, $6 \mathrm{M} \mathrm{LiCl}$ ) of $+193 \mathrm{mV}$ vs SHE was determined from the Nernst equation and thermodynamic data (eqs S1-S3, Supporting Information). The high concentration of the electrolyte was used to prevent evaporation of the droplet. Dispensing and aspiration of the liquid from/into the micropipette was controlled via a microinjector (PV820 Pneumatic PicoPump, WPI, Worcester, MA) and argon gas $(99.998 \%$, BOC Industrial Gases, U.K.). The diameter of the deposited droplet (typically $20-50 \mu \mathrm{m}$ in diameter, $2-30 \mathrm{pL}$ volume) was controlled via combination of pressure and deposition time. The micropipette and the liquid was changed every $6-10$ th droplet deposition. A micrograph in Figure 1c shows a microdroplet deposited on a basal plane surface of a graphene monolayer. The droplet/graphene interfacial area was determined using either GXCapture 7.3 software (GT Vision Ltd., U.K.) or NIS Elements (D) software (Nikon Metrology, UK Ltd.). The experiments were carried out at ambient temperature $\left(25-29^{\circ} \mathrm{C}\right)$, which was recorded and accounted for in $k^{0}$ calculations.

Flake Preparation. All samples were prepared by micromechanical exfoliation of graphite. Briefly, natural graphite crystals (NGS, Naturgraphit, GmbH, Germany) were repeatedly cleaved using high-tack, low-stain cello-tape to obtain a flat and pristine graphite surface, which was pressed onto clean $\mathrm{Si} / \mathrm{SiO}_{2}$ wafers. The tape was dissolved in MIBK and wafers washed with IPA, blow-dried with nitrogen, and baked on a hot plate for a couple of minutes. A fresh flake surface was exposed by a final peel using the above tape. Suitable flakes were found using optical microscopy and the wafer was immobilized on a microscope slide so electrical contact could be made, as described above.

Monolayer graphene has been previously shown to be susceptible to damage by fracture, upon deposition of a liquid, when prepared via the above procedure, but stable on polymercoated substrates. ${ }^{19}$ The reasons behind the monolayer stability/instability are currently under investigation. Full details of the flake preparation are found in Supporting Information.

Flake Characterization. The number of graphene layers in thin flakes was estimated using optical microscopy, reliable for up to 6-7 graphene layers providing there is a variety of comparable thin flakes present on the sample. ${ }^{50}$ Figure $1 \mathrm{c}$ shows an example of a monolayer graphene, with a bilayer ribbon stretching from the top left corner toward the middle and some thicker (3-7) terraced surfaces in the lower part of flake. The optical microscopy (brightfield and darkfield) was also used to locate areas of pristine basal plane of the flake surface for droplet deposition. Optical assessment of the samples was supported by Raman spectroscopy carried out using Renishaw RM Mkl 1000 spectrometer with a $633 \mathrm{~nm}$ HeNe laser ( $\sim 1 \mathrm{~mW}$ power) and an Olympus $\mathrm{BH}-2$ microscope at $500 \times$ magnification, reliably distinguishing between mono-, bi-, and trilayer graphene, and also providing valuable information about doping and presence of lattice defects. ${ }^{51,52}$ Raman spectra of a monolayer, bilayer and three thicker flakes are shown in Figure 7a. Finally, atomic force microscopy (AFM), using a Dimension Icon and SNL-10 Si-tip on a $\mathrm{Si}_{3} \mathrm{~N}_{4}$ cantilever in a PeakForce tapping mode and MultiMode 8 software (Bruker UK Ltd.), was employed to determine the number of layers in thick flakes based on the minimum graphite interlayer spacing of $0.3358 \mathrm{~nm} .^{53}$ A representative AFM image of a thicker flake and its cross section are shown in Figures 7 , panels $b$ and $c$, respectively.

Elemental analysis of both atmosphere-aged and freshly cleaved graphite surface was obtained using XPS and EDX techniques. One sample was exposed to ambient environment for longer than 1 month (aged sample), whereas the other was cleaved several times (using the tape above) until a pristine shiny graphite surface was exposed (cleaved sample) and placed immediately into XPS, EDX vacuum chamber, respectively. XPS analysis was performed at 5 different surface sites using the largest available spot size $\left(400 \mu \mathrm{m}^{2}\right)$ on K-Alpha monochromated (Al-1486 eV) X-ray Photoelectron Spectrometer system (Thermo Fisher Scientific, Inc.). All XPS data were analyzed and quantified using CasaXPS Software (version 2.3.16, www.casaxps.com). Details of the EDX instrumentation and analysis are found in Supporting Information.

Conflict of Interest: The authors declare no competing financial interest.

Acknowledgment. The authors thank EPSRC (grant references: EP/I005145/1, EP/K039547/1 and EP/K016954/1) for financial 
support. The authors also thank Dr. Anders Barlow at nanoLAB (Newcastle University) for XPS measurement, and Greg Auton, Sheng Hu and Huafeng Yang, all from Manchester University, for their help with sample preparation and characterization.

Supporting Information Available: Micropipette preparation, reference electrode potential determination, Nicholson method, cyclic voltammetry fitting, mediator-free blank voltammetry, AFM of the stable and collapsed microdroplets, flake preparation procedure, determination of the redox mediator diffusion coefficients, kinetics-droplet size correlation, comparison of the raw and analyzed kinetic data, uncompensated resistance, comparison of electrode kinetics on basal and edge plane of graphite, and X-ray photoelectron spectroscopy (XPS) and energydispersive X-ray spectroscopy (EDX) analysis of atmosphere-aged and freshly cleaved graphite surface. This material is available free of charge via the Internet at http://pubs.acs.org.

\section{REFERENCES AND NOTES}

1. Mayorov, A. S.; Gorbachev, R. V.; Morozov, S. V.; Britnell, L.; Jalil, R.; Ponomarenko, L. A.; Blake, P.; Novoselov, K. S.; Watanabe, K.; Taniguchi, T.; et al. Micrometer-Scale Ballistic Transport in Encapsulated Graphene at Room Temperature. Nano Lett. 2011, 11, 2396-2399.

2. Balandin, A. A. Thermal Properties of Graphene and Nanostructured Carbon Materials. Nat. Mater. 2011, 10, 569-581.

3. Lee, C.; Wei, X.; Kysar, J. W.; Hone, J. Measurement of the Elastic Properties and Intrinsic Strength of Monolayer Graphene. Science 2008, 321, 385-388.

4. Novoselov, K. S.; Geim, A. K.; Morozov, S. V.; Jiang, D.; Zhang, Y.; Dubonos, S. V.; Grigorieva, I. V.; Firsov, A. A. Electric Field in Atomically Thin Carbon Films. Science 2004, 306, 666-669.

5. Geim, A. K. Graphene: Status and Prospects. Science 2009, 324, 1530-1534.

6. Novoselov, K. S.; Fal'Ko, V. I.; Colombo, L.; Gellert, P. R.; Schwab, M. G.; Kim, K. A Roadmap for Graphene. Nature 2012, 490, 192-200.

7. Nair, R. R.; Blake, P.; Grigorenko, A. N.; Novoselov, K. S.; Booth, T. J.; Stauber, T.; Peres, N. M. R.; Geim, A. K. Fine Structure Constant Defines Visual Transparency of Graphene. Science 2008, 320, 1308.

8. Moser, J.; Barreiro, A.; Bachtold, A. Current-Induced Cleaning of Graphene. Appl. Phys. Lett. 2007, 91.

9. Topsakal, M.; Aahin, H.; Ciraci, S. Graphene Coatings: An Efficient Protection from Oxidation. Phys. Rev. B: Condens. Matter Mater. Phys. 2012, 85.

10. Wang, Y.; Li, Z.; Wang, J.; Li, J.; Lin, Y. Graphene and Graphene Oxide: Biofunctionalization and Applications in Biotechnology. Trends Biotechnol. 2011, 29, 205-212.

11. Lee, J. K.; Smith, K. B.; Hayner, C. M.; Kung, H. H. Silicon Nanoparticles-Graphene Paper Composites for Li lon Battery Anodes. Chem. Commun. (Cambridge, U.K.) 2010, 46, 2025-2027.

12. Wang, X.; Zhi, L.; Müllen, K. Transparent, Conductive Graphene Electrodes for Dye-Sensitized Solar Cells. Nano Lett. 2008, 8, 323-327.

13. Stoller, M. D.; Park, S.; Yanwu, Z.; An, J.; Ruoff, R. S. Graphene-Based Ultracapacitors. Nano Lett. 2008, 8, 3498-3502.

14. Brownson, D. A. C.; Kampouris, D. K.; Banks, C. E. Graphene Electrochemistry: Fundamental Concepts through to Prominent Applications. Chem. Soc. Rev. 2012, 41, 6944-6976.

15. McCreery, R. L. Advanced Carbon Electrode Materials for Molecular Electrochemistry. Chem. Rev. (Washington, DC, U.S.) 2008, 108, 2646-2687

16. Li, W.; Tan, C.; Lowe, M. A.; Abruña, H. D.; Ralph, D. C. Electrochemistry of Individual Monolayer Graphene Sheets. ACS Nano 2011, 5, 2264-2270.

17. Valota, A. T.; Kinloch, I. A.; Novoselov, K. S.; Casiraghi, C.; Eckmann, A.; Hill, E. W.; Dryfe, R. A. W. Electrochemical Behavior of Monolayer and Bilayer Graphene. ACS Nano 2011, 5, 8809-8815.
18. Sharma, R.; Baik, J. H.; Perera, C. J.; Strano, M. S. Anomalously Large Reactivity of Single Graphene Layers and Edges toward Electron Transfer Chemistries. Nano Lett. 2010, 10, 398-405.

19. Toth, P. S.; Valota, A.; Velicky, M.; Kinloch, I.; Novoselov, K.; Hill, E. W.; Dryfe, R. A. W. Electrochemistry in a Drop: A Study of the Electrochemical Behaviour of Mechanically Exfoliated Graphene on Photoresist Coated Silicon Substrate. Chem. Sci. 2014, 5, 582-589.

20. Brownson, D. A. C.; Munro, L. J.; Kampouris, D. K.; Banks, C. E. Electrochemistry of Graphene: Not Such a Beneficial Electrode Material? RSC Adv. 2011, 1, 978-988.

21. Goh, M. S.; Pumera, M. The Electrochemical Response of Graphene Sheets Is Independent of the Number of Layers from a Single Graphene Sheet to Multilayer Stacked Graphene Platelets. Chem.-Asian J. 2010, 5, 2355-2357.

22. Xie, X.; Zhao, K.; Xu, X.; Zhao, W.; Liu, S.; Zhu, Z.; Li, M.; Shi, Z.; Shao, Y. Study of Heterogeneous Electron Transfer on the Graphene/Self-Assembled Monolayer Modified Gold Electrode by Electrochemical Approaches. J. Phys. Chem. C 2010, 114, 14243-14250.

23. De, S.; Coleman, J. N. Are There Fundamental Limitations on the Sheet Resistance and Transmittance of Thin Graphene Films? ACS Nano 2010, 4, 2713-2720.

24. Zhang, B.; Fan, L.; Zhong, H.; Liu, Y.; Chen, S. Graphene Nanoelectrodes: Fabrication and Size-Dependent Electrochemistry. J. Am. Chem. Soc. 2013, 135, 10073-10080.

25. Ambrosi, A.; Bonanni, A.; Pumera, M. Electrochemistry of Folded Graphene Edges. Nanoscale 2011, 3, 2256-2260.

26. Brownson, D. A. C.; Banks, C. E. Cvd Graphene Electrochemistry: The Role of Graphitic Islands. Phys. Chem. Chem. Phys. 2011, 13, 15825-15828.

27. Valota, A. T.; Toth, P. S.; Kim, Y. J.; Hong, B. H.; Kinloch, I. A.; Novoselov, K. S.; Hill, E. W.; Dryfe, R. A. W. Electrochemical Investigation of Chemical Vapour Deposition Monolayer and Bilayer Graphene on the Microscale. Electrochim. Acta 2013, 110, 9-15.

28. Tan, C.; Rodríguez-López, J.; Parks, J. J.; Ritzert, N. L.; Ralph, D. C.; Abruña, H. D. Reactivity of Monolayer Chemical Vapor Deposited Graphene Imperfections Studied Using Scanning Electrochemical Microscopy. ACS Nano 2012, 6, 3070-3079.

29. Ritzert, N. L.; Rodríguez-López, J.; Tan, C.; Abruña, H. D. Kinetics of Interfacial Electron Transfer at Single-Layer Graphene Electrodes in Aqueous and Nonaqueous Solutions. Langmuir 2013, 29, 1683-1694.

30. Güell, A. G.; Ebejer, N.; Snowden, M. E.; MacPherson, J. V.; Unwin, P. R. Structural Correlations in Heterogeneous Electron Transfer at Monolayer and Multilayer Graphene Electrodes. J. Am. Chem. Soc. 2012, 134, 7258-7261.

31. Nicholson, R. S. Theory and Application of Cyclic Voltammetry for Measurement of Electrode Reaction Kinetics. Anal. Chem. 1965, 37, 1351-1355.

32. Klingler, R. J.; Kochi, J. K. Electron-Transfer Kinetics from Cyclic Voltammetry. Quantitative Description of Electrochemical Reversibility. J. Phys. Chem. 1981, 85, 17311741.

33. Randles, J. E. B. A Cathode Ray Polarograph. Part II. The Current-Voltage Curves. Trans. Faraday Soc. 1948, 44, 327338.

34. Bard, A. J.; Faulkner, L. R. Electrochemical Methods. Fundamentals and Applications, 2nd ed.; John Wiley \& Sons, Inc.: New York, 2001.

35. Patel, A. N.; Collignon, M. G.; Oconnell, M. A.; Hung, W. O. Y.; McKelvey, K.; MacPherson, J. V.; Unwin, P. R. A New View of Electrochemistry at Highly Oriented Pyrolytic Graphite. J. Am. Chem. Soc. 2012, 134, 20117-20130.

36. Edwards, M. A.; Bertoncello, P.; Unwin, P. R. Slow Diffusion Reveals the Intrinsic Electrochemical Activity of Basal Plane Highly Oriented Pyrolytic Graphite Electrodes. J. Phys. Chem. C 2009, 113, 9218-9223.

37. Lai, S. C. S.; Patel, A. N.; McKelvey, K.; Unwin, P. R. Definitive Evidence for Fast Electron Transfer at Pristine Basal Plane Graphite from High-Resolution Electrochemical Imaging. Angew. Chem., Int. Ed. 2012, 51, 5405-5408. 
38. Banks, C. E.; Davies, T. J.; Wildgoose, G. G.; Compton, R. G. Electrocatalysis at Graphite and Carbon Nanotube Modified Electrodes: Edge-Plane Sites and Tube Ends Are the Reactive Sites. Chem. Commun. (Cambridge, U.K.) 2005, 829-841.

39. McDermott, M. T.; Kneten, K.; McCreery, R. L. Anthraquinonedisulfonate Adsorption, Electron-Transfer Kinetics, and Capacitance on Ordered Graphite Electrodes: The Important Role of Surface Defects. J. Phys. Chem. 1992, 96, 3124-3130.

40. Li, Z.; Wang, Y.; Kozbial, A.; Shenoy, G.; Zhou, F.; McGinley, R.; Ireland, P.; Morganstein, B.; Kunkel, A.; Surwade, S. P.; et al. Effect of Airborne Contaminants on the Wettability of Supported Graphene and Graphite. Nat. Mater. 2013, 12, 925-931.

41. Hardcastle, T. P.; Seabourne, C. R.; Zan, R.; Brydson, R. M. D.; Bangert, U.; Ramasse, Q. M.; Novoselov, K. S.; Scott, A. J. Mobile Metal Adatoms on Single Layer, Bilayer, and Trilayer Graphene: An ab Initio DFT Study with van der Waals Corrections Correlated with Electron Microscopy Data. Phys. Rev. B: Condens. Matter Mater. Phys. 2013, 87.

42. Zan, R.; Ramasse, Q. M.; Bangert, U.; Novoselov, K. S. Graphene Reknits Its Holes. Nano Lett. 2012, 12, 39363940.

43. Rooney, M. B.; Coomber, D. C.; Bond, A. M. Achievement of Near-Reversible Behavior for the $\left[\mathrm{Fe}(\mathrm{CN})_{6}\right]^{3-/ 4-}$ Redox Couple Using Cyclic Voltammetry at Glassy Carbon, Gold, and Platinum Macrodisk Electrodes in the Absence of Added Supporting Electrolyte. Anal. Chem. 2000, 72, 3486-3491.

44. Meyer, J. C.; Geim, A. K.; Katsnelson, M. I.; Novoselov, K. S.; Booth, T. J.; Roth, S. The Structure of Suspended Graphene Sheets. Nature 2007, 446, 60-63.

45. Wang, Q. H.; Jin, Z.; Kim, K. K.; Hilmer, A. J.; Paulus, G. L. C.; Shih, C. J.; Ham, M. H.; Sanchez-Yamagishi, J. D.; Watanabe, K.; Taniguchi, T.; et al. Understanding and Controlling the Substrate Effect on Graphene Electron-Transfer Chemistry via Reactivity Imprint Lithography. Nat. Chem. 2012, 4, 724-732.

46. Elias, D. C.; Nair, R. R.; Mohiuddin, T. M. G.; Morozov, S. V.; Blake, P.; Halsall, M. P.; Ferrari, A. C.; Boukhvalov, D. W.; Katsnelson, M. I.; Geim, A. K.; et al. Control of Graphene's Properties by Reversible Hydrogenation: Evidence for Graphane. Science 2009, 323, 610-613.

47. Pierce, C.; Ewing, B. Localized Adsorption on Graphite Surfaces. J. Phys. Chem. 1967, 71, 3408-3413.

48. Schedin, F.; Geim, A. K.; Morozov, S. V.; Hill, E. W.; Blake, P.; Katsnelson, M. I.; Novoselov, K. S. Detection of Individual Gas Molecules Adsorbed on Graphene. Nat. Mater. 2007, 6, 652-655.

49. Davies, T. J.; Moore, R. R.; Banks, C. E.; Compton, R. G. The Cyclic Voltammetric Response of Electrochemically Heterogeneous Surfaces. J. Electroanal. Chem. 2004, 574, 123152.

50. Blake, P.; Hill, E. W.; Castro Neto, A. H.; Novoselov, K. S.; Jiang, D.; Yang, R.; Booth, T. J.; Geim, A. K. Making Graphene Visible. Appl. Phys. Lett. 2007, 91.

51. Ferrari, A. C. Raman Spectroscopy of Graphene and Graphite: Disorder, Electron-Phonon Coupling, Doping and Nonadiabatic Effects. Solid State Commun. 2007, 143, 47-57.

52. Malard, L. M.; Pimenta, M. A.; Dresselhaus, G.; Dresselhaus, M. S. Raman Spectroscopy in Graphene. Phys. Rep. 2009, 473, 51-87.

53. Walker, P. L.; McKinstry, H. A.; Wright, C. C. X-Ray Diffraction Studies of a Graphitized Carbon-Changes in Interlayer Spacing and Binding Energy with Temperature. Ind. Eng. Chem. 1953, 45, 1711-1715. 